DOI: 10.12957/demetra.2016.22446

\title{
Diversidade sexual, gênero e novas formas de organização da família: questões para o ensino e a comensalidade
}

\section{Sexual diversity, gender and new forms of family organization: issues for education and commensality}

Roberta Ribeiro De Cicco ${ }^{\top}$

Eliane Portes Vargas ${ }^{2}$

\begin{abstract}
I Fundação Oswaldo Cruz, Programa de Pós-Graduação Stricto Sensu em Ensino em Biociências e Saúde do Instituto Oswaldo Cruz. Rio de Janeiro-RJ, Brasil.

${ }^{2}$ Fundação Oswaldo Cruz, Laboratório de Educação em Ambiente e Saúde e Programa de Pós-Graduação Stricto Sensu em Ensino em Biociências e Saúde do Instituto Oswaldo Cruz. Rio de Janeiro-RJ, Brasil.
\end{abstract}

Correspondência / Correspondence Roberta Ribeiro De Cicco E-mail: robertarcicco@gmail.com

\section{Resumo}

Este artigo discute a problemática da diversidade sexual, envolvendo as transformações das identidades de gênero no exercício da sexualidade e os novos cenários de organização da família contemporâneos, relacionados às indagações e aos desafios presentes no ensino de ciências, bem como das práticas educacionais em suas interseções com a saúde onde se incluem as práticas alimentares. Tal problemática ainda se apresenta pouco contemplada como interesse e objeto de estudo nos diferentes contextos. Propõe-se abordá-la de modo não isolado dos saberes e conteúdos que conformam tais práticas, tendo em vista o lugar socialmente legitimado da escola nos processos formativos e na construção do conhecimento científico. As reflexões de cunho qualitativo conjugam as perspectivas sociológicas e antropológicas, tendo por base o levantamento de documentos oficiais, projetos e/ou iniciativas que tematizam a diversidade sexual nas escolas no que tange ao fortalecimento, respeito e legitimidade da conjugalidade entre pessoas do mesmo sexo. A discussão aponta as atuais conquistas sociais ao direito de entidade familiar, somadas às tensões que permeiam o debate acerca da diversidade sexual envolvendo as políticas públicas de educação.

Palavras-chave: Ensino de Ciências. Diversidade Sexual. FamíliaEscola, Família-Comensalidade.

\section{Abstract}

This article discusses the issue of sexual diversity, involving the transformation of gender identities in the practice of sexuality 
and the new organizational scenarios of contemporary family as related to inquiries and challenges in the teaching of science and the educational practices in their intersections with health, including eating habits. This issue has not been the interest and object of study often enough in these different contexts. In the present analysis, this issue is approached together with the knowledge and content that shape these practices with a view to socially legitimized role of school in educational processes and in the construction of scientific knowledge. The qualitative nature of reflections combine sociological and anthropological perspectives based on the collection of data on official documents, projects and / or initiatives that make sexual diversity a theme addressed in schools in order to strengthen the respect and legitimacy of conjugality between persons of the same sex. The debate points out the current social achievements as regards the right to form a family, added to the tensions that pervade the debate on sexual diversity involving public education policies.

Key words: Science Education. Sexual Diversity. Family-School, Family-Edibility.

\section{Comida de mães; famílias sem mães: considerações iniciais}

As intersecções entre comida, gênero e família não são objeto específico e privilegiado da presente análise. No entanto, parecem-nos instigante, e esta é nossa intenção: pensar na problemática da diversidade, envolvendo o exercício da sexualidade e as transformações das identidades de gênero, de modo não isolado dos saberes e dos conteúdos científicos disseminados nas práticas de ensino e de saúde, incluindo a das práticas alimentares. Esses saberes conformadores das práticas acabam por desconsiderar a subjetividade como mediadores do conhecimento científico, bem como os novos cenários de organização da família na atualidade.

Ainda que não se observe maior interesse na abordagem do tema da diversidade sexual no campo denominado de Alimentação e Cultura, onde a comensalidade ganha sentido como prática social, estudos culturais contemporâneos destacam o quanto saberes e práticas alimentares são reveladores das dinâmicas das relações familiares e das hierarquias de gênero. ${ }^{1}$ Sendo assim, a problematização particularizada da diversidade sexual, mediante as atuais conquistas sociais dos direitos relacionados à entidade familiar e o debate contemporâneo acerca da diversidade sexual na escola, pode ser um caminho fecundo para se refletir mais amplamente sobre práticas e saberes (sejam em saúde ou entre escolares). Trata-se de duas instâncias sociais (família e escola) relevantes para a socialização e construção das identidades sociais. 
Nessa direção, torna-se pertinente indagar como a diversidade sexual se expressa, por exemplo, como parte das relações sociais no âmbito da comensalidade. Tendo em vista seus diferentes aspectos e particularidades no terreno da cultura, a designação "comida de mãe", ${ }^{1}$ no singular, exprime um determinado modelo de família no qual o lugar feminino se apresenta como construído social e culturalmente. Então, como pensar uma família plural constituída por mais de uma mãe? Ou mais de um pai?

Muitas outras questões podem ser desdobradas a partir desta indagação nos contextos das práticas alimentares e de saúde e/ou do ensino/escolares. No entanto, não nos deteremos nelas em profundidade; interessa-nos, justamente, a possibilidade de haver interconexões entre elas, sobretudo quanto aos modelos e concepções de família que norteiam as práticas de ensino e de saúde. Basta lembrar que a escola aciona tradicionalmente a família com o intuito de tratar junto aos pais de questões sobre o ensino, a aprendizagem e o desempenho escolar de seus filhos. Mas como os diferentes atores inseridos no cotidiano da escola se dirigem a uma família composta por duas mães? Ou dois pais? Consideram esse arranjo diferente como sendo uma família?

Tendo em vista as questões brevemente aqui assinaladas, este trabalho visa contribuir, particularmente, para uma melhor compreensão dos elementos em jogo presentes no atual debate sobre diversidade sexual, bem como identificar possíveis lacunas existentes nas formulações e aplicabilidades de políticas públicas de ensino/educação. Destaca, portanto, os desafios da incorporação do novo cenário de identidades e práticas sexuais e arranjos familiares, nas propostas e projetos voltados ao cotidiano escolar contemporâneo. Nesta direção, reafirma-se ser necessário ampliar o entendimento sobre o tema, bem como a identificação das tensões que o envolvem com vistas aos aprimoramentos necessários da ação no âmbito do ensino e das práticas de saúde.

\section{Antecedentes e contextualização do tema}

Uma das temáticas inerentes à sexualidade que transcende os conteúdos abordados no ensino de ciências, imersa no cotidiano escolar, é a denominada "diversidade sexual", que tem sido palco de disputa de sentidos e tornou-se mais visível recentemente por sua divulgação na mídia. Este tema traz consigo debates também fomentados no campo das Ciências Sociais, cujos objetivos estão voltados à consolidação de uma cultura de respeito à diversidade de orientação sexual e de identidade de gênero. No Brasil, as diferenças sociais, os estudos de gênero, a sexualidade e relações étnico-raciais incentivaram os conteúdos curriculares e as práticas docentes a não reforçarem as diferenças sociais entre homens e mulheres, brancos e negros, heterossexuais e homossexuais.

Tendo por base a literatura no âmbito das Ciências Sociais e Humanas nas discussões em torno dessa temática, observa-se, em muitos casos, episódios de discriminação da população homoafetiva, apontando uma persistente intolerância aos direitos sexuais. Segundo pesquisa da Unesco sobre 
juventude e sexualidade, o Brasil apresenta crescente índice de atitudes e valores homofóbicos no espaço escolar, embora se observe também um aumento no interesse em favor de ações mais abrangentes no enfrentamento da violência, do preconceito e de discriminação contra lésbicas, gays, bissexuais, travestis e transexuais. ${ }^{2,3}$

A escola tem sido historicamente considerada, a partir dos valores e modelos de conduta por ela transmitidos e produzidos na sociedade pela educação formal, como um local de debates e desenvolvimento de propostas neste âmbito. Portanto, tem papel decisivo, embora não exclusivo, na construção do conhecimento, no desenvolvimento de ações visando a tal construção. No cenário contemporâneo, reivindica-se que a relevância desta atuação se afirme por meio de práticas pautadas no respeito às diferenças sociais, incluídas aquelas presentes na experiência da sexualidade, e no enfrentamento dos preconceitos em suas mais variadas vertentes. Pode-se destacar, em meio às propostas vigentes, que a família tem sido apontada como uma parceira em potencial destes projetos, cabendo ser problematizada, no entanto, a visão de família que se encontra na base dessas propostas e ações. Ou seja, pretende-se que a escola se traduza, para a sociedade, como um espaço institucional privilegiado para a convivência social e para o estabelecimento de relações subjetivas favoráveis à promoção não só do conhecimento científico, mas também ao respeito à diversidade muitas vezes apenas tangenciadas e associadas às práticas de saúde no âmbito da escola.-Mas qual a relevância deste tema no âmbito das práticas de ensino e do contexto escolar?

Na medida em que a temática da diversidade encontra-se associada a episódios de discriminação da população homoafetiva e à intolerância aos direitos sexuais dos cidadãos, parte-se do pressuposto de que as discussões em torno da sexualidade, e especialmente da diversidade sexual no cenário escolar, envolvem valores culturais e percepções modelados pelas representações sociais sobre o tema.

Gestores institucionais, professores, os próprios estudantes e seus familiares apresentam interpretações diferenciadas em relação à temática, tornando complexos não só os debates a respeito, mas o desenvolvimento de propostas neste âmbito, sobretudo aquelas que visam ampliar as discussões sobre a abordagem do tema no contexto do ensino. Torna-se relevante compreender como as propostas voltadas à temática da diversidade sexual são recebidas, discutidas e desenvolvidas no cenário escolar, cujos modelos e valores transmitidos atuam decisivamente na construção do pensamento critico, bem como são percebidas e dialogadas em conjunto com os diversos núcleos e constituições familiares presentes na comunidade escolar.

Neste sentido, reafirma-se a necessária problematização em torno da relação escola-família no que tange ao tema da diversidade sexual e aponta-se como um fazer necessário o descortinar de aspectos pouco visíveis na formulação de propostas voltadas para a escola por meio da formulação de políticas públicas. 


\section{Percurso de análise}

Estas reflexões conjugam as perspectivas sociológicas e antropológicas, considerando os estudos realizados do campo das Ciências Sociais e Humanas sobre o tema, com os quais dialoga. Nesta direção, é conduzida a partir de uma abordagem qualitativa que se caracteriza por privilegiar o estudo das ações sociais individuais e grupais em uma perspectiva crítica. ${ }^{4}$ A abordagem qualitativa, presente em pesquisas na área de ensino, alcança uma aproximação fundamental e de intimidade entre sujeito e objeto, influenciando diretamente no contexto da pesquisa e garantindo a compreensão de fenômenos e fatos da análise. Ou seja, o objeto da pesquisa qualitativa é construído progressivamente a partir da interação dos dados coletados do campo e as suas análises. ${ }^{4-6}$ No âmbito das políticas públicas, a pesquisa qualitativa tem muito a contribuir na medida em que tende a considerar os diferentes aspectos de determinada situação, relacionando-os ao contexto geral, formulando proposições ligadas à ação e à prática. ${ }^{6}$

O material obtido foi reunido por meio de levantamento realizado em documentos oficiais e/ ou projetos associados à temática da diversidade sexual nas escolas, a saber: a Lei de Diretrizes e Bases, os Parâmetros Curriculares Nacionais, a Coleção "Diversidade Sexual na Educação: problematizações sobre a homofobia nas escolas", o Programa "Brasil sem Homofobia" e o Projeto "Gênero e Diversidade na Escola". A análise também comporta a identificação de iniciativas e projetos, que fortalecem o respeito à diversidade sexual e a legitimidade da conjugalidade entre pessoas do mesmo sexo, garantindo-lhes o direito de entidade familiar, somados à indicação de questões intrínsecas à sexualidade e à diversidade sexual. Estas, por sua vez, permeiam o cenário escolar, fazendo-se também presentes as novas relações familiares como parte da sociedade contemporânea.

O trabalho desenvolve-se a partir desses referenciais sociais, visando ao argumento de que o tema da diversidade sexual e suas implicações na relação família-escola encontram-se ausentes do contexto escolar. Este raciocínio se encontra fundamentado nos estudos que versam sobre família como instituição social e suas transformações na sociedade, mediante as diferentes formas de organização familiar que hoje se apresentam na sociedade. No entanto, a família, quando acionada no contexto da escola, parece ser considerada como uma categoria abstrata e universal que não corresponde à complexa rede de relações sociais que a caracterizam. Ademais, as referências à família sugerem prevalecer um modelo de família conjugal moderna composta pela tríade paimãe-filho. 


\section{A família como instituição social e as diferentes formas de organização familiar: fundamentos e perspectivas}

A família, como participativa nas ações e projetos desenvolvidos nos espaços escolares, e caracterizada como instituição social, vem sofrendo modificações ao longo do desenvolvimento da sociedade contemporânea, cujas alterações têm influenciado decisivamente na forma de interação familiar, constituindo diferentes modos de relacionamento e de ressignificação. ${ }^{7}$

As instituições da sociedade são em geral concebidas como formas naturalizadas de organização da vida coletiva, refletindo padrões de comportamentos definidos. Desta forma, a instituição normatiza, legaliza e legitima os comportamentos do indivíduo em sociedade, proporcionando estabilidade e segurança nas trocas sociais. Sendo assim, a instituição pode ser definida como um conjunto de normas, regras, valores e procedimentos sociais, presentes e reconhecidos na sociedade, definindo aquilo que é ou não legítimo, bem como assumindo papel influente nas relações entre os indivíduos. São elementos fundamentais para a compreensão do funcionamento e organização de uma sociedade. De tal modo, a instituição social pode ser definida como uma "ferramenta" de socialização com o objetivo de gerenciar as relações interpessoais. ${ }^{7}$

Como exemplos de instituições sociais, podemos citar a Educação, a Família, o Estado e a Igreja. A Educação, por exemplo, é uma instituição social associada à transmissão de valores, normas e conhecimentos produzidos pelo homem, com o objetivo de formar cidadãos para a convivência em sociedade, ou seja, para o cumprimento de seu papel social. ${ }^{8}$ Sendo a Família também uma instituição, ela se apresenta como a primeira instância de sociabilidade na constituição do indivíduo. Envolve as relações de parentesco, a regulamentação social das atividades biológicas (sexo e reprodução), bem como suas vivências, em que a pessoa inicia sua construção da identidade refletida em valores familiares normalmente impostos pela sociedade. Todavia, as mudanças na sociedade têm alterado as formas de interação social dentro das famílias, constituindo novos modos de relacionamento entre indivíduo/ambiente e entre indivíduo/indivíduo. Tais mudanças são importantes na ressignificação da família enquanto instituição social. ${ }^{7,8}$

No processo de ressignificação da família, observa-se uma tendência na naturalização da díade conjugal heterossexual com filhos como forma elementar de família. Identifica-se que há necessidade em dissolver tal naturalidade, de modo a perceber a família como instituição que vem sofrendo modificações e conceber de forma variável as microinstituições - paternidade, maternidade, casamento -, privilegiando os diversos arranjos presentes na sociedade contemporânea. ${ }^{9}$

A partir o final do século XX, os estudos sobre família têm demarcado a diversidade das estruturas e configurações familiares, demonstrando, assim, as múltiplas organizações social e biológica na sociedade. ${ }^{9-11}$ Ao longo dos últimos anos, acompanhamos no Brasil modificações 
significativas nas representações sociais relativas à família. A busca pela legitimidade social e jurídica para as relações amorosas entre pessoas do mesmo sexo a partir da década de 1990, os avanços tecnológicos e as expressivas transformações sociais, políticas culturais e econômicas têm contribuído para redesenhar a família contemporânea e discutir o ideário de família conjugal. Questões como divórcio, monoparentalidade, autonomia em relação à conjugalidade e reprodução, e redefinição dos papéis de gênero e conjugais, ainda contribuíram para mudanças na forma como a família e o casamento são percebidos pela sociedade, analisados, ainda, sob a ótica heteronormativa. ${ }^{10}$

Na realidade empírica, observamos que a categoria "Família”, como instituição social, tem sido constituída cultural e socialmente a partir de um modelo conjugal ou nuclear tradicional (pai, mãe e filhos/as). Contudo, percebe-se que há diferentes organizações familiares, com grupos maiores ou menores que o modelo nuclear tradicional, famílias matrifocais, formadas basicamente por mães e filhos e os novos arranjos familiares que vêm surgindo a partir da união entre pessoas do mesmo sexo. Pela existência desta amplitude de definições nas formas familiares, não podemos negar o surgimento de novas modalidades de constituição familiar conjugal na sociedade moderna. A família pode, portanto, ser compreendida como uma instituição em constante mudança, sofrendo impacto das transformações do campo corpo social e onde novos arranjos são observados. ${ }^{11}$ Isto indica que, apesar de existir um modelo hegemônico de família, os desdobramentos da diversidade de arranjos familiares começam a ganhar espaço e certamente influenciam as dinâmicas das relações socais, inclusive dentro do espaço escolar.

\section{Discussão sobre as diferenças na experiência da sexualidade: debates contemporâneos, novos cenários de práticas e regulação}

Os debates das questões de gênero nas políticas públicas de educação, com destaque para as demandas em torno da diversidade sexual, surgiram no campo da Saúde Pública e, posteriormente, em setores da sociedade civil e da educação, ganhando visibilidade e iniciativas no campo legislativo e dos direitos a partir dos anos de $1990 .^{12}$ Assim, as lutas pela igualdade de gênero e também pelo respeito à diversidade sexual têm sido constantes desde o século XX. A afirmação da diversidade sexual, bem como as mudanças que envolvem as definições de masculino e feminino, ganharam destaque a partir das conquistas de direitos políticos dos movimentos feministas e LGBTT (Lésbicas, Gays, Bissexuais, Travestis e Transexuais). Essas ações possibilitaram maior visibilidade às questões de gênero e sexualidade tanto na área da saúde quanto nas definições das agendas e políticas governamentais. ${ }^{13}$ 
Ainda predominam, no entanto, atitudes e convenções sociais naturalizadas com relação à sexualidade voltadas à heteronormalização das práticas sexuais, cujas ações restringem o desenvolvimento das potencialidades dos indivíduos. Essas convenções partem do sentido de senso comum de que possa existir um sujeito desviante em contraponto a um sujeito de referência, estabelecendo-se o par heterossexualidade/homossexualidade como oposição decisiva e definidora de práticas e de sujeitos. ${ }^{14,15}$ Sobre estes olhares e questões, a autora ${ }^{16}$ chama atenção para o modo como a cultura das sociedades modernas não admite um sujeito ser outra coisa além de um homem ou uma mulher, refletindo um caráter heterossexual dos desejos e relações sexuais conhecido como heteronormatividade. Constitui, desta forma, um conjunto de relações de poder, que privilegia e promove a heterossexualidade em detrimento das demais orientações sexuais.

O silêncio, o bullying e a invisibilização das potencialidades são formas de controle social e relações de poder sobre determinados grupos, agindo contra quaisquer manifestações de comportamento na orientação sexual ou na expressão do gênero. Deste modo, pessoas com desejos e comportamentos homoafetivos muitas vezes ocultam suas manifestações de afeto e relações amorosas e, até pouco tempo, lhes era negado o reconhecimento da união estável, bem como de entidade familiar.

O reconhecimento social e jurídico da união estável para as relações amorosas entre casais do mesmo sexo veio ganhando espaço nas discussões políticas desde o final dos anos 1960, adquirindo maior visibilidade no final dos anos 80 e início dos anos 90. Países da Europa, desde já, possuíam amparo legal para as uniões homoafetivas, enquanto que nos Estados Unidos e França ainda permaneciam os debates acerca da mudança do entendimento legal do casamento, na tentativa de contemplar todas as formas de relações amorosas..$^{10}$

No Brasil, até meados dos anos 1990, a principal luta voltava-se à proibição de discriminação por orientação sexual, em qualquer de suas formas, sendo reivindicada, somente posteriormente, a conquista dos direitos civis para os casais homoafetivos, embora não se tenha obtido êxito junto à Constituição Federal de 1988. As tentativas, portanto, foram redirecionadas para as esferas estadual e municipal, em suas constituições e leis orgânicas. ${ }^{10}$

Mais uma tentativa brasileira de amparar legalmente as uniões homoafetivas foi difundida no ano de 1994, ${ }^{a}$ embora tenha sido rapidamente reprimida pelas lideranças católicas e pela percepção de que se exigia, além de tudo, aprovação do Congresso Nacional. A partir dessa iniciativa, a reivindicação para as uniões homoafetivas adentrou os cenários políticos e esteve embasada em projeto de lei que legalizaria e ampararia essas uniões, embora soubessem de antemão das inúmeras resistências que receberiam de diversos setores da sociedade brasileira. ${ }^{10}$

a Mais precisamente na campanha presidencial de Luiz Inácio Lula da Silva, do Partido dos Trabalhadores (PT). 
A partir de 1995, em parceria com especialistas e lideranças do movimento homossexual, definiu a proposta do Projeto de Lei ${ }^{\circ} 1.151 / 95,{ }^{\mathrm{b}}$ que em linhas gerais "disciplina a união civil entre pessoas do mesmo sexo e dá outras providências". Esse projeto foi a primeira tentativa de regulamentação da convivência entre pessoas do mesmo sexo, ${ }^{10,17}$ embora não fosse no momento a principal reinvindicação, que ainda se voltava à proibição de discriminação por orientação sexual. Desta forma, a proposta do reconhecimento das relações amorosas estáveis entre pessoas do mesmo sexo repercutiu na mídia e na sociedade, ganhando força nos movimentos homossexuais, embora tenha tido resistência de grupos religiosos em defesa da família e moralização da sociedade.

Até o final de 1998, o projeto de lei havia sido apenas aprovado na Comissão Especial, não sendo levado a cargo da Câmara dos Deputados. Na forma de substitutivo, o projeto aprovado na Comissão Especial sofreu algumas alterações, principalmente no que dizia respeito ao nome do instrumento jurídico, que de união civil passou a ser parceria civil registrada. Este se desvinculou da perspectiva de casamento homoafetivo e/ou união estável, embora assegurasse os efeitos patrimoniais decorrentes de tal parceria, mas garantindo os direitos humanos. Como modificação mais substantiva, um adendo de que nos contratos de parceria civil registrada seriam vedadas quaisquer disposições sobre adoção, tutela ou guarda de crianças ou adolescentes em conjunto, mesmo que filhos de um dos parceiros. ${ }^{10}$

Apesar destas e outras modificações no substitutivo aprovado na Comissão Especial, notavase a intenção de distinguir os tipos de união e assegurar aos contratantes da parceria civil registrada os direitos próprios à esfera da família, com exceção dos direitos relativos à adoção mencionados anteriormente..$^{10}$ Percebe-se, portanto, que apesar das tentativas de denominar a união homoafetiva como uma parceria civil registrada, as uniões eram vistas e constituídas como uma nova modalidade de família, na medida em que garantia os mesmos direitos às pessoas casadas ou que viviam em união estável, embora não tivesse tal pretensão. Para a autora do Projeto Lei n⿳0 1.151/95, a deputada Marta Suplicy, negar esse amparo legal às uniões homoafetivas poderia comprometer ainda a liberdade de orientação sexual. Afirmava, ainda, que o projeto não tinha o objetivo de caracterizar o casal homoafetivo como uma unidade familiar, o que amenizava os ânimos com a bancada religiosa, na medida em que não pretende causar nenhum impacto sobre a estrutura familiar.

Após inúmeras audiências e discursos parlamentares acerca do Projeto Lei, o reconhecimento social e jurídico da união estável entre casais do mesmo sexo veio a ser julgado e aprovado pelo Supremo Tribunal Federal (STF) no dia 5 de maio de 2011, representando mais uma vitória para

b O Projeto de Lei no $1.151 / 95$, composto pro 18 artigos, passou a ser constituído como projeto e previa o direito à herança, à sucessão, benefício previdenciário, seguro-saúde conjunto, declaração conjunta de imposto de renda e direito à nacionalidade no caso de estrangeiros. 
a comunidade LGBTT. As ações foram ajuizadas na Corte, respectivamente, pela ProcuradoriaGeral da República e pelo governador do Rio de Janeiro, Sérgio Cabral. O relator, ministro Ayres Brito, também argumentou a favor do reconhecimento da união homoafetiva, com base no artigo $3^{-}$, inciso IV da Constituição Federal, ${ }^{c}$ no sentido de excluir qualquer interpretação que impedisse a união entre pessoas do mesmo sexo como entidade familiar (p. 132) ${ }^{\mathrm{d}}{ }^{18,19}$

A ministra da Cultura Marta Suplicy, na época, aliada à comunidade LGBTT, continuou apoiando a comunidade homossexual com a apresentação do anteprojeto do Estatuto da Diversidade Sexual, ${ }^{\text {e } q u e ~ d e f e n d i a, ~ e n t r e ~ m u i t o s ~ p o n t o s, ~ a ~ l i v r e ~ o r i e n t a c ̧ a ̃ o ~ s e x u a l ~ e ~ i d e n t i d a d e ~ d e ~ g e ̂ n e r o ~ c o m o ~}$ direitos fundamentais. Somando-se a este ponto, demais direitos são apresentados: livre escolha de modelo de entidade familiar; união homoafetiva com os mesmos direitos assegurados à união heteroafetiva; direito ao exercício da parentalidade, em relação aos filhos biológicos, adotados ou socioafetivos, individualmente ou em união homoafetiva e; proposta para que as instituições de ensino adotem materiais didáticos que não reforcem a discriminação, bem como programem suas atividades escolares comemorativas, atentando para a multiplicidade de formações familiares, de modo a evitar qualquer constrangimento dos alunos(as) filhos(as) de famílias homoafetivas. ${ }^{20}$

Em análise às propostas da ministra supracitada à união homoafetiva, bem com para as instituições de ensino, observa-se, portanto, uma correlação estreita entre estes e os projetos e iniciativas de inserção e discussão da temática "diversidade sexual no espaço escolar".

\section{0 reconhecimento das invisibilidades e as iniciativas visando à atuação na Escola}

Tem crescido a percepção da importância da educação e do ensino como viés para o enfrentamento de situações relativas à discriminação homoafetiva. A escola vem sendo convocada a contribuir para o enfrentamento dessas questões, sendo um espaço decisivo para a construção do pensamento crítico e de práticas pautadas no respeito à diversidade e aos direitos humanos. ${ }^{3}$ "Diversidade" é o termo utilizado para definir as múltiplas expressões da sexualidade, e permite demonstrar que não existe um padrão que possibilite definir o envolvimento afetivo e sexual de um indivíduo em relação ao outro. Assim, a necessidade do debate sobre diversidade na escola justifica-

c O Art. 3ํ, Inciso IV, da Constituição Federal de 1988 afirma: "Constituem objetivos fundamentais da República Federativa do Brasil: IV- promover o bem de todos, sem preconceitos de origem, raça, sexo, cor, idade e quaisquer outras formas de discriminação".

d Ação proposta pela Procuradoria Geral da República alegando que, dada a omissão do Legislativo federal sobre o assunto, o não reconhecimento da união homoafetiva estaria contrariando preceitos fundamentais como igualdade, liberdade e o princípio da dignidade da pessoa humana, todos da Constituição Federal.

e O Estatuto da Diversidade Sexual visa promover a inclusão de todos, combater a discriminação e a intolerância por orientação sexual ou identidade de gênero e criminalizar a homofobia, de modo a garantir a efetivação da igualdade de oportunidades e a defesa dos direitos individuais, coletivos e difusos. 
se pela possibilidade de os diferentes atores institucionais transmitirem, refletirem e orientarem a comunidade escolar sobre valores éticos importantes, como respeito e exercício da cidadania. ${ }^{21}$

Discutir tais questões no âmbito da educação torna-se importante na medida em que se observa uma amplitude e incidência de crimes homofóbicos e violência de gênero no Brasil. ${ }^{2}$ Entretanto, ainda há toda uma dificuldade em propor estes debates e inserir questões relativas a gênero, sexualidade, igualdade e diversidade sexual nas propostas curriculares das instituições de ensino. Iniciativas para entrada dessas temáticas na escola têm enfrentado resistência, tanto nas esferas institucionais, como nas políticas. ${ }^{22,23}$

Os debates das questões de gênero nas políticas públicas de educação, com destaque às demandas em torno da diversidade sexual, surgiram no campo da Saúde Pública e posteriormente em setores da sociedade civil e da educação, ganhando visibilidade e iniciativas no campo legislativo e dos direitos a partir dos anos de $1990 .{ }^{12}$ Assim, as lutas pela igualdade de gênero e pelo respeito à diversidade sexual têm sido constantes nas últimas décadas do século XX, quando inúmeros acontecimentos promoveram uma maior visibilidade de questões relacionadas aos gêneros e às sexualidades,, tanto na área da saúde e educação quanto nas definições das agendas e políticas governamentais. ${ }^{13}$

Assim, a partir do final da década de 1990, com a nova LDB - Lei n 9.394/96 e elaboração dos Parâmetros Curriculares Nacionais (PCN) e seus Temas Transversais, que a Educação Sexual na escola - através do tema transversal "Orientação Sexual” - e demais temáticas associadas, tornaramse mais visíveis, alcançando status para o desenvolvimento de projetos e aulas voltados para essa linha da educação. A transversalidade, portanto, permite estabelecer, na prática educativa, uma relação entre o conhecimento sistematizado dos campos disciplinares e a formação e vivências dos cidadãos. ${ }^{24}$ Podemos afirmar que os PCNs possibilitaram um contexto educacional bastante favorável à inclusão da Educação Sexual e da Diversidade Sexual nos currículos do ensino de Ciências e Biologia. ${ }^{25}$

A estruturação do currículo envolve diferentes conteúdos e atividades que normalmente representam as tradições culturais e pedagógicas de uma localidade. Surge, a partir desta perspectiva, a noção associada ao controle do processo pedagógico, ao estabelecimento de metas, prioridades e conteúdos, mantendo um padrão de conhecimento voltado a um públicoalvo específico, com o objetivo de disciplinar o saber e obtenção de resultados. ${ }^{26}$ Assim, pode-se dizer que é o elemento norteador das práticas escolares, uma vez que delimita os objetivos e os critérios de avaliação da ação pedagógica, assim como indica quais conteúdos e metodologias são considerados adequados. .

Numa perspectiva pós-estruturalista, o currículo, evidencia a análise dos conceitos de cultura, linguagem e poder onde os conhecimentos se intercruzam, possibilitando uma associação com as propostas voltadas à educação escolar. ${ }^{26-28}$ Observamos, neste sentido, tentativas de incluir 
questões sociais ao currículo a partir de um conjunto articulado e aberto de temas, que contemple sua complexidade e dinâmica, dando-lhes a mesma importância das áreas convencionais - como os já mencionados Temas Transversais. Esta iniciativa prevê, portanto, que o currículo ganhe flexibilidade ao priorizar as diferentes realidades locais e regionais. ${ }^{29-31}$ Nessa dinâmica, temos o respeito às diferenças, às desigualdades, às identidades e diversidade dos sujeitos e às relações de poder que têm sido incluídos nos currículos atuais através de projetos e propostas educacionais e políticas voltados ao debate destas temáticas e nas iniciativas de formação continuada dos professores.

No âmbito das políticas públicas, como exemplo recente, tivemos o recuo nas diretrizes gerais do PNE - 2011/2020, que substituiu da sua versão atual o texto inicial do Inciso III do Art. 2º que fazia referência à "superação das desigualdades educacionais, com ênfase na promoção da igualdade racial, regional, de gênero e de orientação sexual", sendo substituído por "superação das desigualdades educacionais, com ênfase na promoção da cidadania e na erradicação de todas as formas de discriminação". ${ }^{32}$ Este recuo no texto do PNE demonstra que ainda encontramos setores que enxergam a diversidade sexual como uma afronta ao "controle social" e que pensam as questões de gênero e sexualidade sob uma ótica heteronormativa. Na contramão disto, é preciso reconhecer a pluralidade de concepções em relação ao homem e a mulher, bem como reconhecer que as vivências e experiências são construídas socialmente, podendo apresentar diferentes identidades de gênero.

Outra iniciativa que prevê uma articulação entre os campos da política pública e da educação é o Programa "Brasil sem Homofobia", f que apresenta como objetivos centrais propostas de educação e mudança de comportamento dos gestores públicos, através da implementação de novos parâmetros para a definição das políticas públicas e de um conjunto de ações destinadas à promoção do respeito à diversidade sexual e ao combate às várias formas de violação dos direitos humanos. ${ }^{33}$

No campo do ensino, suas propostas de ações a favor da não discriminação por orientação sexual incluem a elaboração de diretrizes para os sistemas de ensino, apoio à formação inicial e continuada de professores na área da sexualidade, formação de equipes multidisciplinares para avaliação de livros didáticos na tentativa de eliminar aspectos discriminatórios, estímulo à produção de materiais educativos sobre orientação sexual e superação da homofobia, bem como a produção de materiais específicos de professores. ${ }^{33}$ Tais propostas são válidas na medida em que se sabe que são necessárias ainda a implementação de novas diretrizes para a discussão da temática nas instituições de ensino, e que a formação inicial de professores voltadas ao tema ainda

f O Programa "Brasil sem Homofobia - Programa de Combate à Violência e à Discriminação contra GLTB (Gays, Lésbicas, Transgêneros e Bissexuais) e de Promoção da Cidadania de Homossexuais” é uma articulação bem sucedida entre o Governo Federal e a Sociedade Civil Organizada com o objetivo de promover a cidadania de gays, lésbicas, travestis, transgêneros e bissexuais, a partir da equiparação de direitos e do combate à violência e à discriminação homofóbicas, respeitando a especificidade de cada um desses grupos populacionais. 
não é contemplada nas instituições de ensino superior, bem como perpassam por questões de cunho pessoal no que diz respeito às discussões e adoções dessas propostas no campo do ensino. ${ }^{34}$

Dentre as iniciativas de produção de materiais educativos sobre orientação sexual e superação da homofobia e de materiais voltados à prática dos professores no ensino, encontra-se em desenvolvimento a Coleção "Diversidade Sexual na Educação: problematizações sobre a homofobia nas escolas". ${ }^{3} \mathrm{O}$ volume propõe uma série consistente e articulada de reflexões sobre a produção e a reprodução da homofobia na educação, especialmente no contexto da escola e nos espaços ligados a ela, e busca fornecer subsídios para a formulação de políticas públicas na área da educação e do reconhecimento da diversidade.

Somando-se à coleção, temos também como iniciativa o "Projeto Escola Sem Homofobia", "que tem como objetivo contribuir para a implementação do Programa Brasil sem Homofobia pelo Ministério da Educação, através de ações que promovam ambientes favoráveis à garantia dos direitos humanos e do respeito às orientações sexuais e identidade de gênero no âmbito escolar. ${ }^{35}$

O Projeto "Escola sem Homofobia" (ESH), no âmbito da produção de materiais, teve como produto um conjunto de recomendações elaborado para a orientação da revisão, formulação e implementação de políticas públicas que enfoquem a questão da homofobia nos processos gerenciais e técnicos do sistema educacional público brasileiro. Propôs também a incorporação e institucionalização de uma estratégia para trabalhar a homossexualidade de forma mais consistente em contextos educativos, com repercussões nos valores culturais atuais. A estratégia contou com a elaboração de um kit de material educativo - Kit Escola sem Homofobia - abordando aspectos da homo-lesbo-transfobia no ambiente escolar, direcionado para gestores(as), educadores(as) e estudantes, bem como a capacitação de técnicos(as) da educação e de representantes do movimento LGBTT de todos os estados para a utilização apropriada do kit nas comunidades escolares. ${ }^{35}$

O Kit Escola sem Homofobia foi elaborado no intuito de combater a violência contra homossexuais nas escolas públicas do país, sendo destinado à formação dos/das professores(as) em geral, fornecendo-lhes subsídios para trabalharem os temas no ensino médio de seis mil escolas públicas previamente selecionadas. Trata-se de um conjunto de instrumentos didático-pedagógicos voltados à desconstrução de imagens estereotipadas sobre lésbicas, gays, bissexuais, travestis e transexuais, e para o convívio democrático com a diferença no espaço escolar. Cada kit é composto por um caderno, uma série de seis boletins, três audiovisuais com guias, um cartaz e cartas de apresentação para o/a gestor(a) e para o/a educador(a). ${ }^{35}$

g O Projeto Escola sem Homofobia é apoiado pelo Ministério da Educação/Secretaria de Educação Continuada, Alfabetização e Diversidade (MEC/SECAD). Foi planejado e executado em parceria entre a rede internacional Global Alliance for LGBT Education - GALE; a organização não governamental Pathfinder do Brasil; a ECOS - Comunicação em Sexualidade; a Reprolatina - Soluções Inovadoras em Saúde Sexual e Reprodutiva; e a ABGLT - Associação Brasileira de Lésbicas, Gays, Bissexuais, Travestis e Transexuais. Todas as etapas de seu planejamento e execução foram amplamente discutidas e acompanhadas de perto pelo MEC/SECAD. 
A distribuição do Kit Escola sem Homofobia estava prevista para o segundo semestre de 2011 nas seis mil escolas de ensino médio, com um gasto total de $\mathrm{R} \$ 1,8$ milhões na sua produção. Contudo, foi cancelada em maio do mesmo ano após pressão das bancadas religiosas, que convenceram a presidente Dilma Rousseff de que o material fazia "propaganda de orientação sexual" e que o "kit gay" - popularmente assim definido - seria distribuído para crianças com seis anos de idade, quando na verdade era destinado exclusivamente a alunos do ensino médio. O veto na verdade esteve vinculado ao material audiovisual composto por três vídeos: Torpedo, Encontrando Bianca e Probabilidade, enquanto o restante do kit permaneceu com o Ministério da Educação, especificamente a Coordenação-Geral de Educação e Direitos Humanos da Secretaria de Educação Continuada, Alfabetização e Diversidade (SECAD), aguardando parecer final e aprovação. ${ }^{36}$

Entretanto, passados mais de dois anos, ainda não há uma definição para o Projeto Escola sem Homofobia, embora o MEC afirme desenvolver algumas ações para combater a homofobia nas escolas e ter firmado uma parceria com o Fórum de Entidades Nacionais da Psicologia (Fenp) e dez universidades federais, para debater e analisar todos os materiais educativos que abordem preconceitos, violência nas escolas e qualquer tipo de discriminação, entre eles, os materiais do Kit Escola sem Homofobia. Dentre as ações e iniciativas, o MEC procura oferecer apoio a cursos de pós-graduação em parceria com as universidades públicas para professores e gestores, à produção e divulgação de pesquisas, à inclusão da temática de forma adequada nos editais de avaliação e seleção de livros didáticos, à inclusão do debate nos currículos universitários, entre outras iniciativas sobre orientação sexual e da identidade de gênero. ${ }^{36}$

No contexto do respeito à diversidade sexual e como exemplo dessas iniciativas, encontramos o projeto "Gênero e Diversidade na Escola", uma iniciativa bem-sucedida do governo brasileiro em parceria com o Centro Latino-Americano em Sexualidade e Direitos Humanos (CLAM/IMS) e com o British Council, que tem por objetivo promover o debate com professores/as sobre questões relativas a gênero, sexualidade e orientação sexual de forma global e transversal, em torno dos direitos sexuais e de processos sociais baseados em gênero e na orientação sexual. ${ }^{37}$ A proposta do projeto em questão problematiza os conceitos de cultura, diversidade cultural, estereótipo, preconceito e discriminação. As discussões sobre gênero e orientação sexual também se dão numa perspectiva transversal, trazendo reflexões sobre a relação entre sexualidade e sociedade, aventando concepções de corpo, de identidade de gênero e orientação sexual, bem como relações étnico-raciais. No contexto do projeto, a escola é ainda problematizada como um ambiente para eliminação do preconceito e de práticas discriminatórias, onde são discutidas diferentes propostas voltadas à educação sexual. Ressalta-se, ainda, a importância do tema da sexualidade. no ambiente escolar, estar associado às vivências e percepções dos adolescentes que estão mais próximas do universo simbólico dos estudantes. ${ }^{38}$ 
Percebemos, portanto, que muitas das ações e iniciativas no campo do ensino para a discussão da diversidade sexual nas escolas perpassam questões que vão além do alcance institucional, da atuação dos professores(as) e gestores(as) e/ou da elaboração e disseminação de materiais educativos. Perpassam questões que envolvem a Escola e a Família, seja esta considerada tradicional ou embasada pelos novos arranjos familiares da sociedade moderna, como pertencentes à comunidade escolar, tendo, portanto, voz ativa e participativa nas decisões das instituições escolares.

\section{As diferenças na escola, uma problematização necessária: considerações finais}

A escola funciona como um ambiente altamente favorável à sexualidade, pois os alunos estão experimentando novas relações, se conhecendo e conhecendo o sexo oposto. Deve, assim, existir diálogo entre a escola e a família, como alicerce fundamental para o desenvolvimento da sexualidade nos adolescentes, além de atividades sistematizadas e planejadas. Com base nos argumentos expostos, se faz necessária a problematização da relação família-escola quando se trata das diferenças relativas ao gênero e ao sexo que permeiam as vivências escolares e das práticas educacionais em suas interseções com a saúde, onde se incluem as práticas alimentares como ilustrado no início deste artigo. Na expectativa de uma ação pedagógica colaborativa e participativa, tem-se observado, a partir dos anos 1980, uma atuação conjunta de gestores escolares, educadores e especialistas em prol de discussões e propostas que problematizem as situações vividas pelos distintos atores sociais da comunidade escolar, incluindo a família. ${ }^{39,40}$

A família, ao ser convocada a se inserir nos espaços escolares, necessita expandir suas relações com a instituição escolar elencando. Assim, discussões importantes na educação dos filhos, além daquelas tradicionalmente consideradas como relacionadas aos saberes escolares e à saúde. As DSTs, e não somente o HIV/AIDS, a obesidade, a anorexia e os transtornos alimentares diversos - estes últimos particularmente no escopo das preocupações no campo da Alimentação e Cultura - são relevantes por alcançarem a juventude quanto à construção da imagem e apresentação de si e aos ideais de corpo. De modo não excludente a estes, acerca das recentes conquistas sociais, a diversidade sexual e a percepção das diferentes dinâmicas familiares existentes na sociedade contemporânea necessitam estar contempladas nas relações entre família-escola.

Tem-se observado, entretanto, que as propostas de educação em saúde dirigidas à escola estabelecem princípios, objetivos e recomendações para a educação sexual de adolescentes e crianças, sem tematizar a escola como um espaço permeado por relações sociais que o constituem. ${ }^{41}$ Nesse processo de socialização do adolescente, evidencia-se um declínio na participação da família nas questões relativas à sexualidade e à crescente participação das instituições de ensino como locais de integração dos jovens entre os pares. Segundo o autor, ${ }^{42}$ as famílias atuam na educação sexual, mas 
esbarram em preconceitos, em tabus e na vergonha de falar de certos detalhes com os filhos. Além disso, há em muitos casos a não aceitação com relação às escolhas nas condutas e prática sexuais.

Muitas escolas, por sua vez, ainda não estão abertas aos diálogos, seja acerca de questões pedagógicas ou de iniciativas e propostas inovadoras que discutam temas "mais polêmicos" como a diversidade sexual, embora se tenha observado, ao longo dos anos, que a escola estendeu sua área de atuação para domínios que antes eram reservados aos núcleos familiares, como o aparecimento de serviços especializados - educação afetivo-sexual, antidrogas - de amparo às famílias. ${ }^{39}$ Estes empecilhos são em parte oriundos da estrutura da nossa sociedade e dos valores e normas por ela impostos, bem como da própria composição das famílias, que foram se estruturando ao longo do tempo, determinando limites em seu papel em relação à sua atuação na escola, oriundos de ideais distintos decorrentes das diversas formas de organização familiar. ${ }^{40}$

Mesmo diante desses obstáculos, modificações estruturais e no modo de vida das famílias e dos processos escolares têm contribuído para a constituição de um sistema de influências mútuas entre família e escola, onde apostamos encontrar caminhos diversos para o diálogo e implementação cadenciada de iniciativas no âmbito escolar. Partindo de uma análise preliminar das políticas públicas a partir da perspectiva das relações de gênero e o contexto em que estas são produzidas, a literatura sobre o tema ${ }^{12}$ nos aponta que há ainda uma discussão complexa acerca do processo de negociação de reformas, projetos, programas e ações articuladas e disputadas entre o Estado e os movimentos sociais, onde cada qual, com seus interesses, pressiona por novas políticas públicas.

Neste sentido, reafirma-se que a problematização em torno do tema se faz necessária, assim como o descortinar de aspectos invisíveis à compreensão do mesmo, sobretudo as lacunas existentes entre as formulações de políticas públicas e sua aplicabilidade no âmbito do ensino.

\section{Referências}

1. Assunção VK. Comida de mãe: notas sobre alimentação, família e gênero. Cad. Espaço Feminino 2008; 19(1):233-253.

2. Abramovay M, Castro MG, Silva LB. Juventude e sexualidade. Brasília: UNESCO-Brasil; 2004. 426 p.

3. Junqueira RD, organizador. Diversidade sexual na educação: problematizações sobre a homofobia nas escolas. Brasília: Ministério da Educação, Secretaria de Educação Continuada, Alfabetização e Diversidade, UNESCO; 2009. 455 p. Coleção Educação para Todos.

4. Martins HHTS. Metodologia qualitativa de pesquisa. Educação e Pesquisa 2004; 30(2):289-300.

5. Fonseca C. Quando cada caso NÃO é um caso. Rev. Bras. Educação 1999; 10:58-78.

6. Poupart J, Deslauriers J, Groulx L, Laperrière A, Mayer R, Pires AP. A pesquisa qualitativa: enfoques epistemológicos e metodológicos. Petrópolis, RJ: Vozes; 2008. 
7. Ramos DM, Nascimento VG. A família como instituição moderna. Fractal: Rev. Psicol. 2008; 20(2):461-472.

8. Berger PL, Berger B. O que é uma instituição social? In: Foracchi MM. organizadores. Sociologia e sociedade: leituras de introdução à Sociologia. Rio de Janeiro: Livros Técnicos e Científicos, 1978; p. 193-199.

9. Durham ER. Família e reprodução humana. In: Frachetto B, Cavalcanti ML, Heilborn ML, organizadores. Perspectivas antropológicas da mulher. Rio de Janeiro: Zahar; 1983. p. 13-44.

10. Mello L. Novas famílias: conjugalidade homossexual no Brasil contemporâneo. Rio de Janeiro: Garamond; 2005. 232 p.

11. Aries P. História social da criança e da família. $2^{a}$ ed. Rio de Janeiro: Livros Técnicos e Científicos; 1981.

12. Vianna C. Gênero, sexualidade e políticas públicas de educação: um diálogo com a produção acadêmica. Pro-Posições 2012; 23(68):127-143.

13. Freire N, Santos E, Haddad F. Construindo uma política de educação em gênero e diversidade. In: Barreto A, Araújo L, Pereira ME. Gênero e diversidade na escola: formação de professoras/es em gênero, orientação sexual e relações étnico-raciais. Livro de conteúdo. Rio de Janeiro: IMS/UERJ/ Centro Latino Americano em Sexualidade e direitos Humanos; 2009. p. 9-10.

14. Louro GL. Pedagogias da sexualidade. In: Louro GL, organizador. O corpo educado: pedagogias da sexualidade. $3^{\text {a }}$ ed. Belo Horizonte: Autêntica; 2010. p. 07-34.

15. Louro GL. Gênero, sexualidade e educação: uma perspectiva pós-estruturalista. 13 ed. Petrópolis, RJ: Vozes; 2011. p. 61-91.

16. Butler J. Problemas de gênero: feminismo e subversão da identidade. Rio de Janeiro: Civilização Brasileira; 2003.

17. Correia JD. União civil entre pessoas do mesmo sexo (Projeto de Lei 1151/95). Jus Navigandi abr. 1997. [acesso em: 01 abr. 2014]. Disponível em: http://jus.com.br/artigos/554/uniao-civil-entrepessoas-do-mesmo-sexo/2\#ixzz2xgVP6pPN

18. Recondo F. STF aprova por unanimidade reconhecimento da união homoafetiva. O Estado de São Paulo 05 maio 2011. [acesso em: 19 mar. 2014]. Disponível em: http://www.estadao.com.br/noticias/ vidae,stf-aprova-por-unanimidade-reconhecimento-da-uniao-homoafetiva,715367,0.htm

19. Brasil. Supremo Tribunal Federal. Supremo reconhece união homoafetiva. Notícias STF 05 maio 2011. [acesso em: 19 mar. 2014]. Disponível em: http://www.stf.jus.br/portal/cms/verNoticiaDetalhe. asp?idConteudo $=178931$

20. Souza V. Marta Suplicy defende cota para homossexuais e "mudança de sexo" a partir dos 14 anos. O Povo online 12 maio 2013. [acesso em: 20 mar. 2014]. Disponível em: http://blog.opovo.com.br/ ancoradouro/marta-suplicy-defende-extincao-do-dia-das-maes-para-nao-ofender-gays/

21. Kamel L, Pimenta C. Diversidade sexual nas escolas: o que os profissionais de educação precisam saber. Rio de Janeiro: ABIA; 2008. 
22. Vieira VA, Machado BF, Bueno ME, Lewin AM. Gênero e diversidade sexual nas escolas: uma questão de direitos humanos. Carta Capital 17 maio 2015. [acesso em: 01 fev. 2016]. Disponível em: http://www.cartacapital.com.br/sociedade/genero-e-diversidade-sexual-nas-escolas-uma-questaode-direitos-humanos-6727.html

23. Vilela S. Polêmica sobre questões de gênero pode deixar alunos do Recife sem livros. UOL Educação 28 mar. 2016. [acesso em: 30 mar. 2016]. Disponível em: http://educacao.uol.com.br/noticias/2016/03/28/ polemica-sobre-questoes-de-genero-pode-deixar-alunos-do-recife-sem-livros.htm

24. Brasil. Ministério da Educação. Parâmetros curriculares nacionais: terceiro e quarto ciclos: apresentação dos temas transversais. Brasília: MEC/SEF; 1998. 436 p.

25. Furlani J. Educação sexual: quando a articulação de múltiplos discursos possibilita sua inclusão curricular. Perspectiva 2008; 26(1):283-317.

26. Silva TT. Documentos de identidade: uma introdução às teorias do currículo. $3^{a}$ ed. $3^{a}$ reimp. Belo Horizonte: Autêntica; 2011. 156 p.

27. Furlani J. Educação sexual na sala de aula: relações de gênero, orientação sexual e igualdade étnicoracial numa proposta de respeito às diferenças. Belo Horizonte: Autêntica; 2011. 190 p.

28. Ribeiro CM, organizador. Tecendo gênero e diversidade sexual nos currículos da educação infantil. Lavras: UFLA; 2012. 532 p.

29. Brasil. Ministério da Educação. Parâmetros curriculares nacionais: apresentação dos temas transversais. Brasília: MEC/SEP; 1997. 146 p.

30. Brasil. Ministério da Educação. Parâmetros curriculares nacionais: pluralidade cultural e orientação sexual. Brasília: MEC/SEF; 1997.

31. Brasil. Ministério da Educação. Parâmetros curriculares nacionais: terceiro e quarto ciclos: apresentação dos temas transversais. Brasília: MEC/SEF; 1998. 436 p.

32. Silva A. Por que o gênero assusta tanto? Notícias CLAM 30 abr. 2014. [acesso em: 08 maio 2014]. Disponível em: http://www.clam.org.br/destaque/conteudo.asp?cod=11528

33. Brasil. Ministério da Saúde. Conselho Nacional de Combate à Discriminação. Brasil Sem Homofobia: Programa de combate à violência e à discriminação contra GLTB e promoção da cidadania homossexual. Brasília: Ministério da Saúde; 2004. 31 p.

34. De Cicco RR. Potencialidades e limites do ensino das doenças sexualmente transmissíveis: um estudo qualitativo na perspectiva socioantropológica [dissertação]. Rio de Janeiro: Fundação Oswaldo Cruz, Instituto Oswaldo Cruz; 2012. 206 p.

35. Projeto Escola Sem Homofobia. ECOS - Comunicação em Sexualidade [acesso em: 28 mar. 2014]. Disponível em: http://www.ecos.org.br/projetos/esh/esh.asp

36. Chagas A. Dois anos após veto, MEC diz que ainda 'analisa' kit anti-homofobia. Notícias Terra online 17 maio 2013. [acesso em: 28 mar. 2014]. Disponível em: https://noticias.terra.com.br/educacao/ dois-anos-apos-veto-mec-diz-que-ainda-analisa-kit-anti-homofobia,62a3a67b302be310VgnVCM10 000098cceb0aRCRD.html 
37. Pereira ME, Rohden F, Brandt ME, Araújo L, Ohana G, Barreto A, et al. Gênero e diversidade na escola: formação de professoras/es em gênero, sexualidade, orientação sexual e relações étnico-raciais. IMS/UERJ/Centro Latino Americano em Sexualidade e Direitos Humanos; 2007. 108 p.

38. Rohden, F. Gênero, sexualidade e raça/etnia: desafios transversais na formação do professor. Cad. Pesquisa 2009, 39(136):157-174.

39. Nogueira MA. Relação família-escola: um novo objeto na sociologia da educação. XXIII Encontro Anual da ANPOCS; 1999; Caxambu, Minas Gerais.

40. Biázzio SCF, Lima PG. A participação da família no projeto politico-pedagógico da escola. Educere et Educare - Revista de Educação 2009; 4(7):373-385.

41. Fonseca A. Prevenção às DST/AIDS no ambiente escolar. Interface - Comunicação, Saúde, Educação 2002; 6(11):71-88.

42. Kleim TAS. Sexualidade, adolescência e escola: uma abordagem interdisciplinar. IV ENPEC Encontro Nacional de Pesquisa em Educação em Ciências; 25-29 nov. 2003; Bauru, SP. Associação Brasileira de Pesquisa em Educação em Ciências.

Recebido: $12 / 4 / 2016$

Revisado: 28/7/2016

Aceito: 25/8/2016 
